\title{
UNIQUE POLICE TRAINING POLYGON IN TERMS OF ACTIVITY AND TRAINING IMPROVEMENT OF THE INTERVENTION UNITS OF THE POLICE OF THE CZECH REPUBLIC
}

The report describes project works and the purpose of a special training polygon designated for police officers of intervention units of the Police of the Czech Republic. It is a completely unique training facility newly built for the law enforcement officers. It concerns the outstanding project in conditions of the Police of the Czech Republic, which contains extreme situations and conditions which police officers of intervention and special units can meet in their practical performance of service. In the limited extend this applies also for the training of tactics for members of firstly coming patrols and emergency units.

Keywords: police, training polygon, intervention units, layout

\section{Introduction}

The Police of the Czech Republic has never had this type of training area or any similar one. Police officers of special units trained in improvised conditions or travelled abroad after the consent of foreign police bodies in order to train intervention in the most realistic conditions and occasionally compare abilities and training methods with those of special units of foreign law enforcement bodies (e.g. in Lest in Slovakia). The below described training facility is an area especially designated for special units trainings of the Police of the Czech Republic (e.g. Rapid Response Unit, Intervention Units of Regional Police Directorates, Prague Emergency Mobile Unit, Special Public Order Police Units, Regional Public Order Police Units, etc.) and by prior agreement also for members of Emergency Fire Brigade of the Czech Republic, Special Military Forces of the Army of the Czech Republic, Intelligence Services of the Czech Republic etc. The Public Order Police Service Directorate guarantees, administrates and operates the project and is in charge of the registration system [1]. The directorate has issued an operational order for the area and it has provided staff responsible for the communication with the supplier of new windows which are necessary to replace those damaged during the training, then for preparation of situations concerning circumstances of the intervention, operational issues, professional supervision over group of trainees, efficiency of this facility and remedy of possible faults.

\section{Project finances for the modern training polygon development}

This project deals with a construction of a special training polygon, which will be used for the training of intervention units. It is located in Zbiroh in Western Bohemia. In December 2013, the Swiss approved to change the technology of the polygon to a high - rise building complex (Figure 1). Switzerland is represented in the project by the Swiss embassy in Prague.

The total amount exceeds CZK 13 million. The project realisation team was established according to the Police President Order No. 131/2013 [1]. The Project is currently operating at full capacity and it was ceremonially opened in February 2016 with the attendance of the police president and the director of Emergency Fire Brigade. The Project was approved based on a long - standing request of police officers from intervention units for a special simulator, which would enable them to train situations in the most realistic conditions that could occur day by day during their police work. The lack of such a polygon in the Czech Republic was evident, as members of the intervention units had to train on provisional simulators and in situations realised within shooting range areas. The need to fire at targets

\footnotetext{
* Martin Hrinko

Faculty of Safety Engineering, VSB - Technical University of Ostrava and Public Order Police Service Directorate of the Police Presidium of the Czech Republic,

E-mail: martin.hrinko@seznam.cz
} 


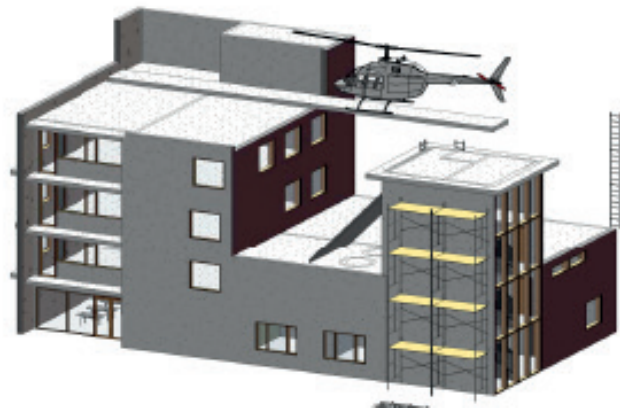

Figure 1 Design of the final image of the training simulator according to the project

(armed perpetrators, etc.) and not to fire after the recognition of other individuals (hostage, non - aligned persons, etc.) in different situations and areas emphasizes the need to continue building these special polygons also in other localitites in the Czech Republic, each with a different layout of the polygon.

Members of the intervention units will be able to train the following activities at one place [2]:

- reconnaissance of the object before the intervention,

tactics of entering the building,

technique of entering the building (from the ground, from the air),

- $\quad$ securing protection for the police officers after they enter the building (in the building, from the area outside the building), movement of police officers in the building,

specific situations and their assessment (offender/hostage),

reaction to shooting in the building,

radio operation,

communication,

command during the intervention,

- target shooting (rifles, short fire arms, over ballistic shield on a regular basis in the ballistic vest and helmet), overcharge, shooting during the daytime, dusk and in the dark, shooting with the use of collimators, milivizors,

- descent from a model pod of a helicopter,

- other tactical and characteristic methods of an intervention.

The project was time consuming due to a demanding communication with the foreign partner (Swiss partner) and a large amount of correspondence, including its detailed translation to English language. Selection procedures resulting in a decision about the construction company followed. The location of the building was chosen by the guarantor of the Project - the Public Order Police Directorate of the Police Presidium of the Czech Republic, because the directorate is the main methodological guarantee of activities of intervention units as it is an organisational part subordinated to the first deputy police president - in the area of a basic unit of the General Directorate of the Emergency Fire Brigade in Zbiroh, thanks to an excellent cooperation among basic units of the above mentioned bodies of the integrated emergency system and the possibility to create a multifunctional area in this location. Representatives of all parties and all heads

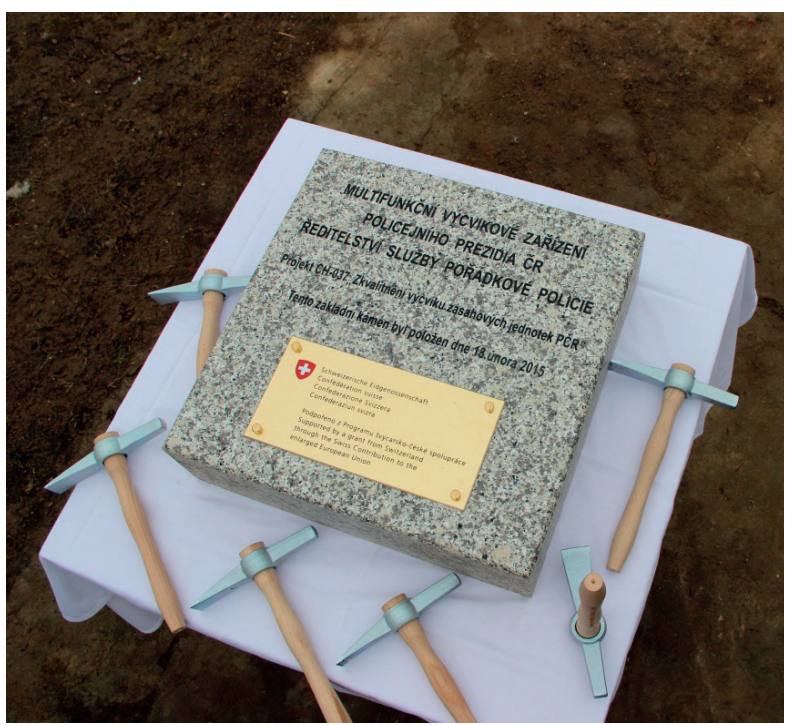

Figure 2 The cornerstone laying ceremony was held on the occasion of the construction commencement of the simulator of the Public Order Police Directorate for the police officers of Intervention Units, 18. 2. 2015 [3] (photo by the Police of the Czech Republic)

of intervention units from the whole country solemnly tapped on the cornerstone in February 2015 (see Figure 2).

\section{Location and situation in the rooms of the simulator}

From a technical point of view, it is a high - rise building complex providing a necessary simulation of the environment. The traverse steel construction is installed on the roof, allowing this construction to sufficiently simulate a real usage of a helicopter, as well as to train any necessary techniques.

The ground floor of the simulator building is in a form of a rectangle $27.35 \mathrm{~m} \mathrm{x} 14.05 \mathrm{~m}$ and it is designed as a five - floor building, approx. $14 \mathrm{~m}$ high, without any basement. Bigger part of this facility is roofed from the second floor, where the steps are located. It has an elevator shaft and a training shaft with imitations of installations (see Figure 3). The northern part of the building above the flats is roofed over the fourth floor. The roof above the flats is accessible from the staircase of the fifth floor which extends over the roof area.

The main entrance to the building - behind the spacious covered approach there is a glassed - in entry hall enabling the access to other premises downstairs. There are also rooms imitating the premises of a restaurant and a bar including their back rooms, a shop, and a store.

The control room is part of the first floor. It is the only room that is heat cladded from the inner side and it is provided with the direct heating devices (see Figure 4). All floors are connected vertically by two areas of steps with a prefabricated staircase located in opposite corners of the building. The one - armed 


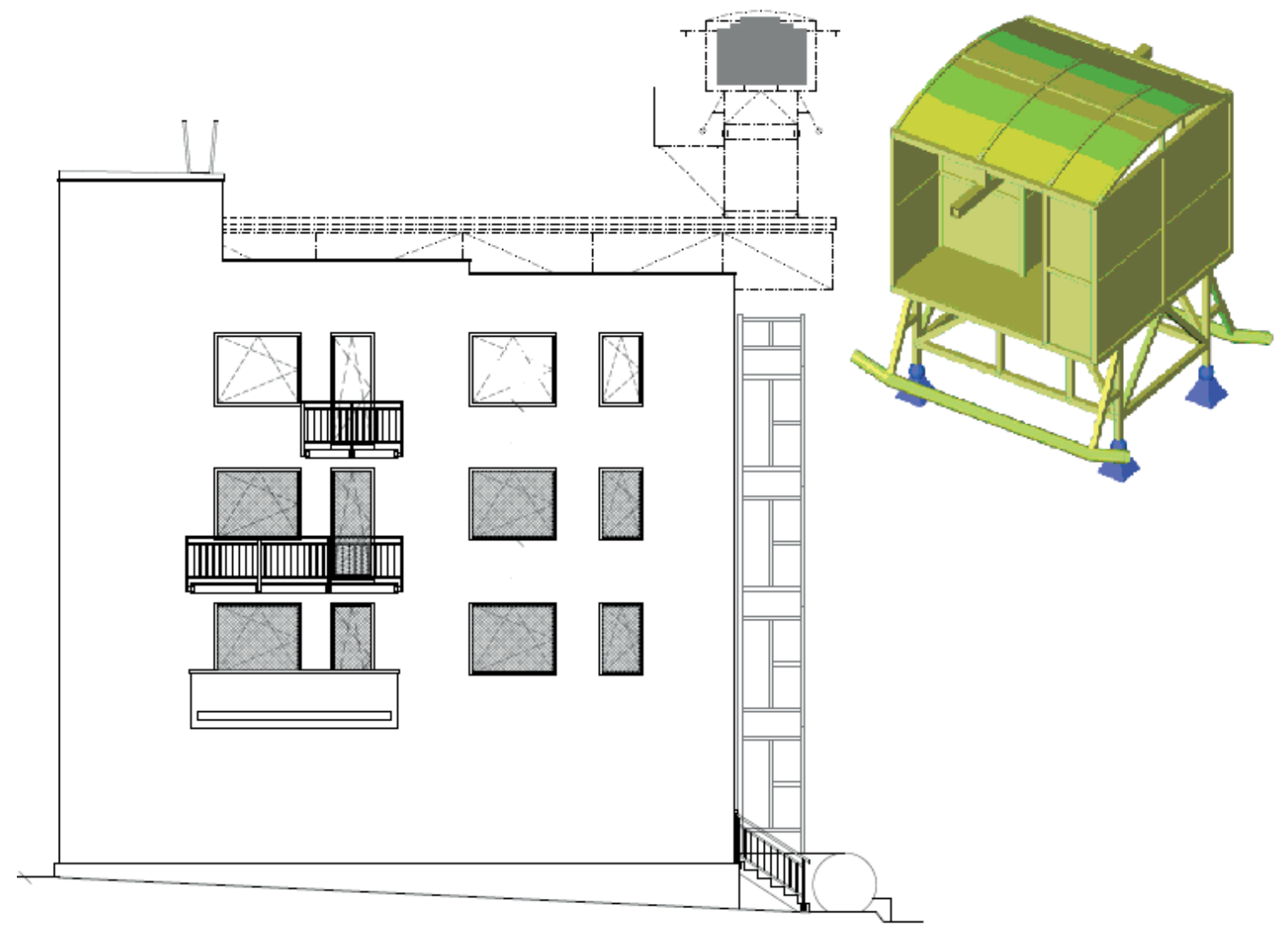

Figure 3 Model of a helicopter board and a location of the building

staircase in the north of the main entrance is accessible by separate entrance from the covered entrance to the building. On the opposite end of the building there is a two - armed staircase with an imitation of an elevator shaft and an opened space 4 floors high with an imitation of a rising conduction of a technical infrastructure, including a steel ladder anchored in the wall of the room. The premises of the restaurant and the bar are also accessible from the outside. Imitations of wells DN 1200 and $1500 \mathrm{~mm}$ are designed to be located on the premises of the store for training reasons. They lead up to the roof over the second floor and they are connected horizontally downstairs with concrete pipe conduit DN $1000 \mathrm{~mm}$ passing through the encircling wall outside, where this pipe continues further as an imitation of a sewage pipe approx. $10 \mathrm{~m}$ long, leading to both sides along the western side of the building.

The second floor is the most variable one. There are two tactical premises in the size of two flats ( 2 rooms + a small kitchen and 2 rooms +1 normal kitchen). It is possible to go outside to a loggia and a balcony from one of these tactical premises (see Figure 5). There are cellar cubicles on one part of this floor, which are formed of flexible and movable crossbar elements. This floor includes a labyrinth accessible from circular passages that are imitations of wells. It is possible to enter the open space by a climbing pipe as well as to enter the cellar part.

The third floor is divided by the flat roof over the second floor with a partial attic. It is divided into two parts of towers of the area $6.3 \times 5.6 \mathrm{~m}$ with a two - armed staircase, an elevator shaft and an open space with a climbing pipe and a part imitating block of flats with a one - armed staircase and two flats (see Figure 6). The bigger flat with a loggia and a balcony is a duplex flat type vertically connected with a steel circular staircase. On the roof, there is a movable construction of a saddle roof with eaves and a dormer - window. The roof is latched in three positions, i.e. at the end of the roof and in the middle, where the western end of the roof is latched without an attic and it also covers the open construction of the imitations of wells. The vertical steel lattice construction is fixed into the construction of the roof over the second floor. This part of the steel constructions set is designated for hanging and rolling during various intervention tactics trainings of special units.

The space of the tower is dispositionally resolved on the fourth floor in the same fashion as on the third floor and it is ended with a flat roof without an attic. The steel lattice construction is fixed into this roof with rails and supporting function for the mobile lattice construction - a footbridge. In the northern part of this 


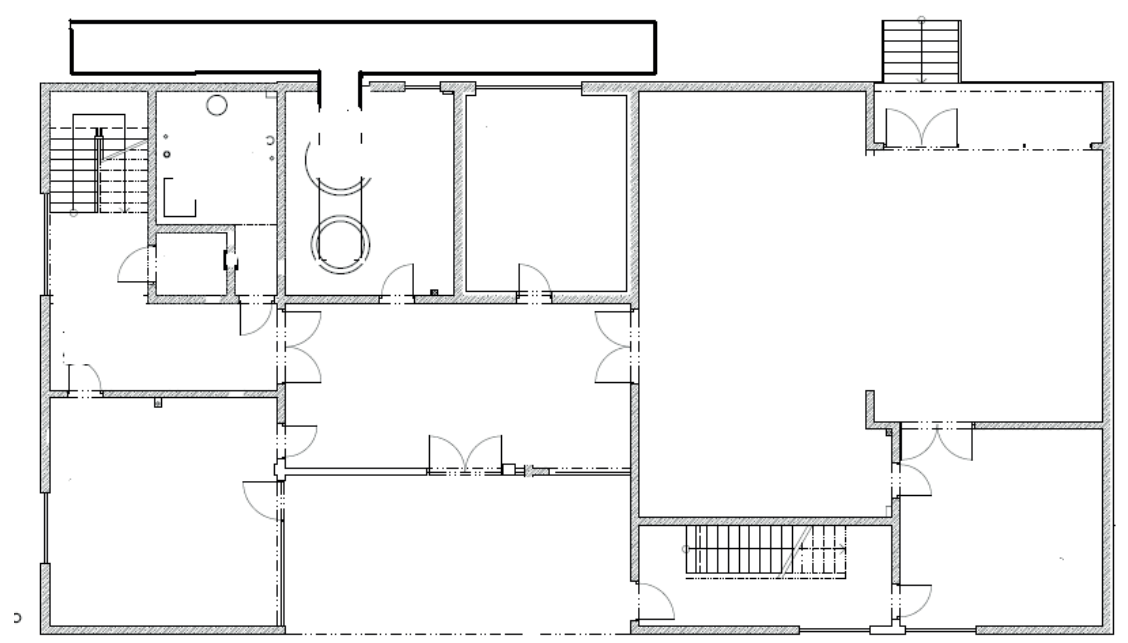

Figure 4 The First floor

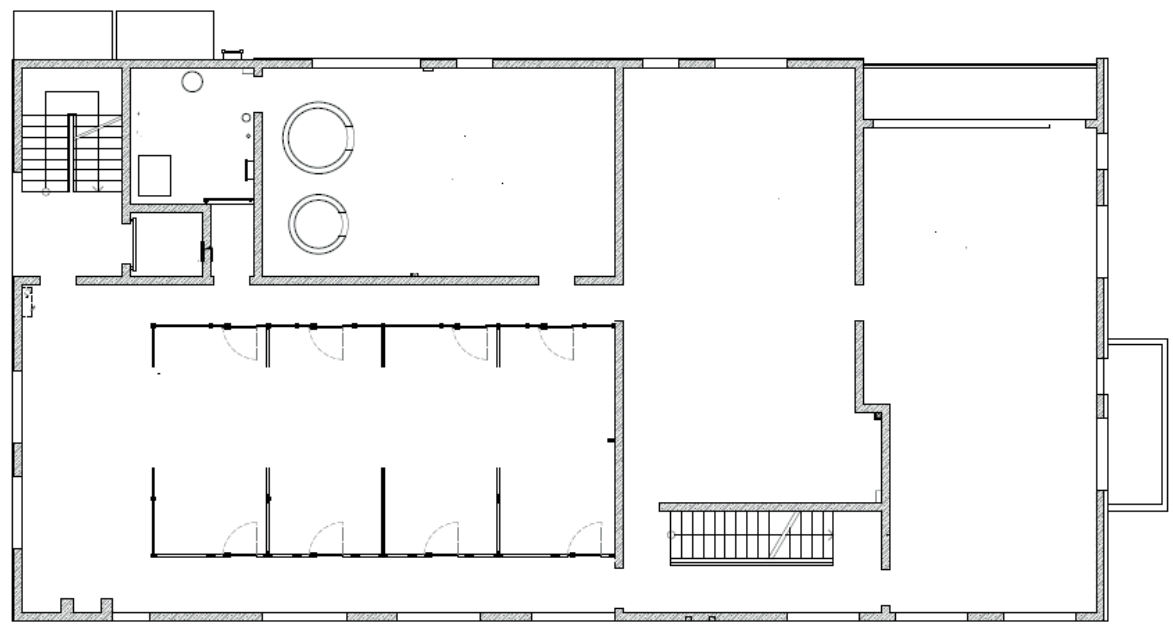

Figure 5 The Second floor

facility there is again a flat with two rooms and a kitchen located as well as the second floor of the duplex with an unconventionally formed gallery connected with the loggia and the small balcony (see Figure 7).

The staircase area containing a one - armed staircase only leads to the fifth floor. From this floor, admission to the roof is possible. The roof has following heights of attics: 0,300 and $600 \mathrm{~mm}$ and the attic high as one floor borders one part of the eastern front face of the building. Sparings for gripping during roping down are made in this peripheral wall in a stripe of approx. $1.6 \mathrm{~m}$ wide. The flat roof over the staircase is without any attics and it leads to the centre of the building. The second lattice steel construction with rails and a supporting function for the mobile lattice construction - a footbridge with a mobile platform imitating a helicopter board is fixed to the roof over flats (see Figure 8). The roofs of various heights is accessible not only from the towers' doors and from the staircase in the northern part, but also by steel ladders fixed into encircling walls and by industrial lattice constructions. In some places roof edges will be equipped with a low banister to provide additional gripping when going down the rope.

The facade of the building is provided with a variety of surface treatments and colourings because of training purposes. The eastern facade is painted on ferroconcrete, the northern one is faced with wooden oak boards and the western and southern walls are provided with the contact heat cladding with the use of a facade polystyrene of $50 \mathrm{~mm}+$ the silicate plaster of the RAL 2012 colour (salmon orange - see Figure 9). 


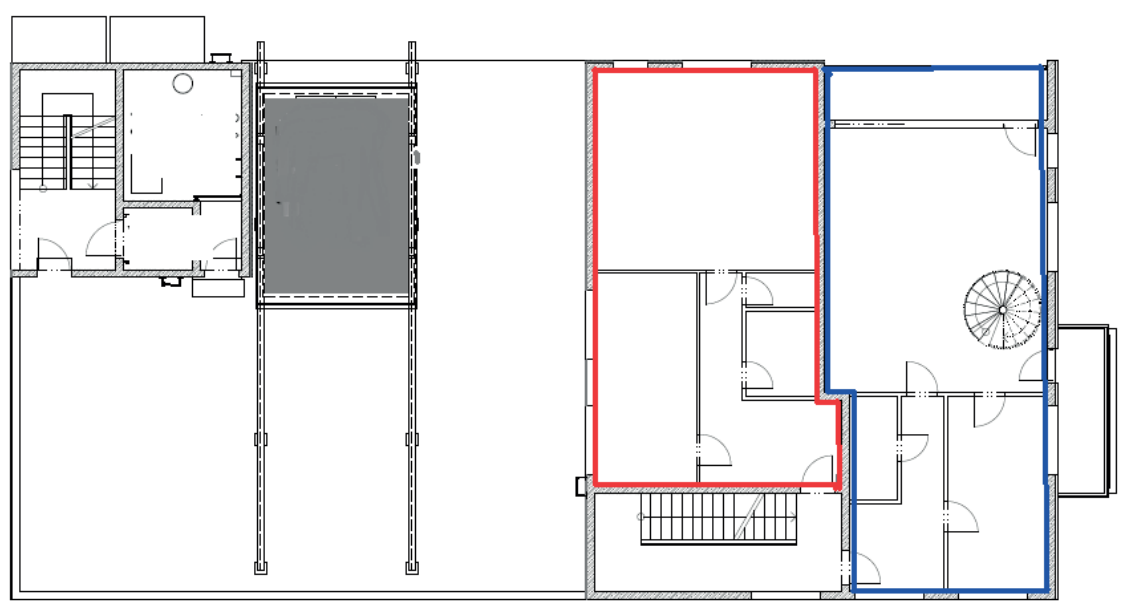

Figure 6 The third floor

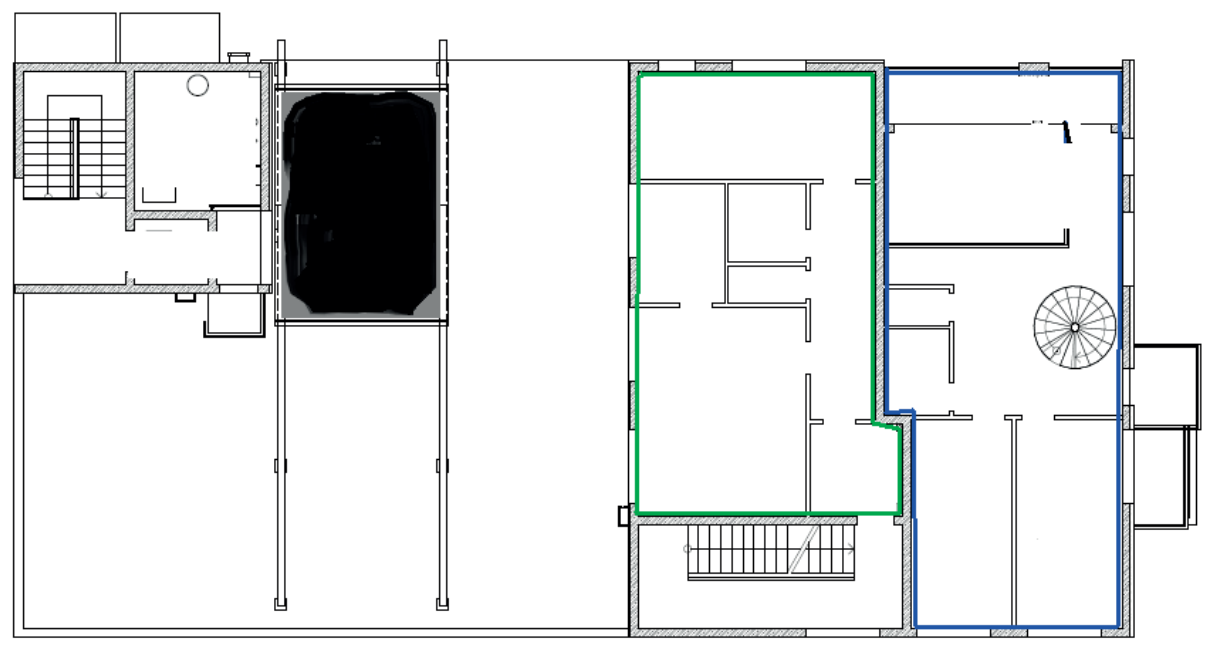

Figure 7 The fourth floor

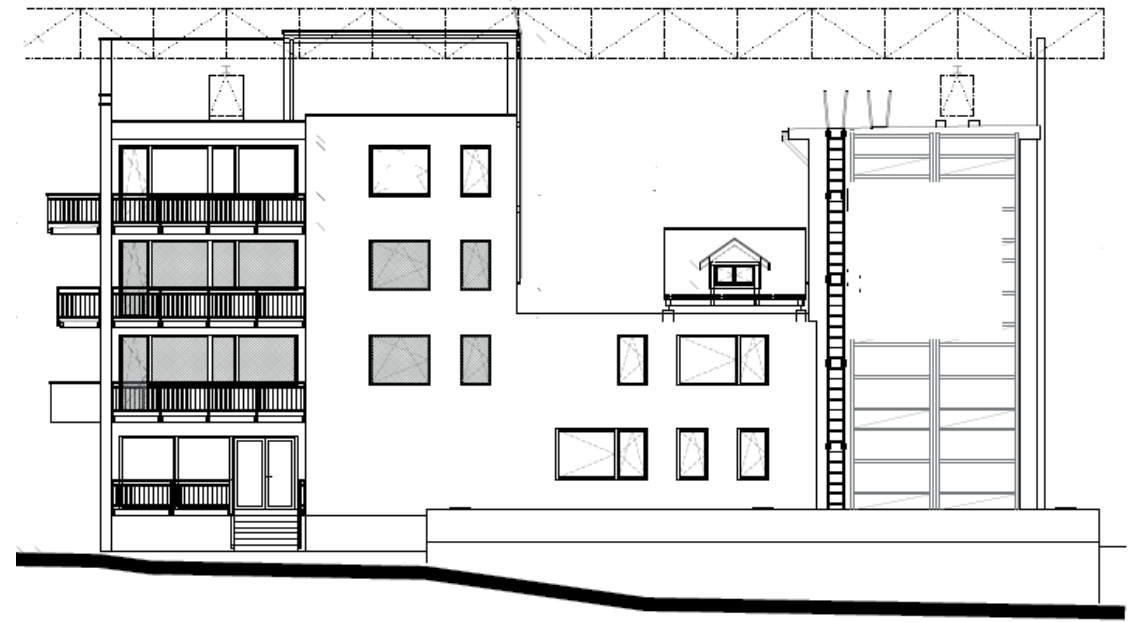

Figure 8 The western view 


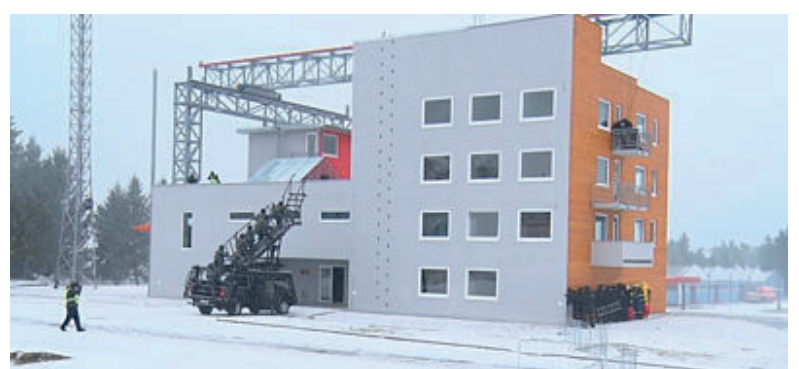

Figure 9 The northern view of the realised construction

\section{Intervention units of the police of the Czech Republic}

Intervention unit members are in brief very well - trained police officers of special units designated for interventions mainly against armed offenders and organised crime (often both), who are aware of the extent and especially punishableness (sentencing) of their actions and therefore not willing to give up, they resist actively, very often using firearms; they also have the necessary technology to protect themselves from being detected and detained. The Police of the Czech Republic has in total 8 seats of intervention units in the whole country, each of them has several tens of police officers with special equipment and they are directly subordinated to the deputy regional director for an external service in the following regions:

- Moravia and Silesia,

- South Moravia,

- South Bohemia,

- Pilsen,

- Usti nad Labem,

- Hradec Kralove,

- Central Bohemia,

- Capital city of Prague.

The deputy regional director for external service is directly subordinated and responsible for the activities and the fulfilment of tasks of the intervention unit to the regional director (to be exact, to the director of the regional police directorate). Intervention units are deployed not only on the territory of one region, but they are prepared to go to other regions beyond their service territory. Intervention units still have their competences according to the original format of borders of the so - called police regions, as this system was effective in the Czech Republic in

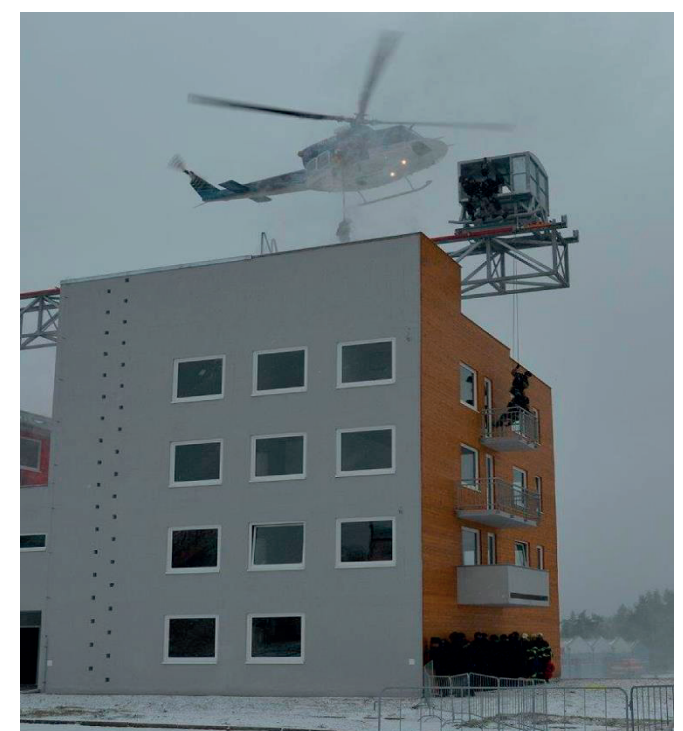

Figure 10 During the ceremonial opening a helicopter of the Aviation Service of the Police of the Czech Republic was engaged in the presentation of the intervention unit

connection with the original layout (e.g. Intervention units of the Moravian and Silesian Region perform their activities also in the territory of the Olomouc Region - originally the territory of the North Moravian Region).

\section{Conclusion}

This report introduces information about the effort of the Public Order Police Service Directorate of the Police Presidium of the Czech Republic to create plans and to help by the project grants to build a polygon assigned for special police unit trainings, especially for intervention units (see Figure 10). This type of a training area has not been available up until now in this form and in such complexity within the whole territory of the Czech Republic. The whole project cost approximately CZK 20 million. We would like to thank the project donator, the country of Switzerland, for its cooperation and financial support, without which this project could not have been realised. The integral part of the project includes also a brief description of the organisation and seats of Intervention Units, in order to gain more comprehensive insight on the topic.

\section{References:}

[1] Binding Instruction of the Police President No. 217/2008. Police Presidium of the Czech Republic, Prague, December 2008.

[2] HRINKO, M.: Basic Tactic of Police Activities (Monographic Publication). University Mimeographed, Mining University - Technical University of Ostrava, Ostrava, p. 74, 2005.

[3] HRINKO, M.: Public Order Police Service Directorate - Methodology and Support of the Public Order Police (Monographic Publication). Mining University - Technical University of Ostrava, Printing Office of the Ministry of Interior of the Czech Republic, Prague, p. 160, 2015 (in edition). 